\title{
PENINGKATAN KETERAMPILAN MOTORIK HALUS MELALUI KEGIATAN MENGGUNTING MEDIA DAUN Di KELAS A TK TUNAS HARAPAN KECAMATAN TAPUNG HILIR
}

\author{
Rastutiti ${ }^{1}$, Zulfah $^{2}$, Yolanda Pahrul ${ }^{3}$ \\ Program Studi PG-PAUD, Universitas Pahlawan Tuanku Tambusai \\ e-mail : rastutitapung@gmail.com
}

\begin{abstract}
Abstrak
Penelitian ini bertujuan untuk meningkatkan motorik halus anak melalui kegiatan menggunting media daun di kelas A TK Tunas Harapan. Hal ini dilatar belakangi oleh rendahnya kemampuan Motorik Halus anak pada indikator menggunting lengkung. Penelitian ini merupakan penelitian tindakan kelas (PTK), instrumen yang digunakan lembar observasi yang berbentuk ceklis dan dokumentasi, waktu pelaksanaanya dari tanggal 12 April 2021 sampai 21 April 2021, subjek penelitian yakni 12 anak kelas A yang terdiri dari 6 anak laki-laki dan 6 anak perempuan dan di laksanakan dalam 2 siklus yakni siklus 1 dan siklus II. Pada tahap pratindakan persentase rata-rata ketercapaian anak baru mencapai $52.08 \%$, Hasil penelitian Siklus I persentase yang dicapai sebesar 60,87\%, dan pencapaian peningkatan keterampilan motorik halus anak pada Siklus II sebesar $84,95 \%$. Kesimpulan penelitian melalui kegiatan mengguntig media daun dapat meningkatkan motorik halus anak di kelas A TK Tunas Harapan Tapung Hilir.
\end{abstract}

Kata Kunci: Peningkatan Motorik Halus Anak, Pegiatan Menggunting, Media Daun.

\section{Abstract}

This study aims to improve children's fine motor skills through leaf cutting activities in class A TK Tunas Harapan. This is motivated by the low fine motor skills of children on the curved cutting indicator. This research is a classroom action research (CAR), the instrument used is an observation sheet in the from of a checklist and documentation, the implementation time is from April 12, 2021 to April 21, 2021, the research subjects are 12 class $A$ achildren consisting of 6 boys and boys girl and carried out in 2 sycles namely sicle I and sycle II. And the pre-action stage, the average percentage of children's achievement only reached $52,08 \%$, the results of the research an cycle I the percentage achieved was $60,87 \%$, and the achievement of improving childrens fine motor in cycle II was $84,95 \%$. The conclusion of the study trough leaf cutting activities can improve the fine motor skills of children in class A TK Tunas Harapan Tapung Hilir.

Keywords: Fine Motor Improvement of Children,Cutting Activities, Media Leaf

\section{PENDAHULUAN}

Anak usia dini merupakan individu yang sedang mengalami proses pertumbuhan dan perkembangan yang sangat pesat. Bahkan dikatakan sebagai 
lompatan perkembangan (Mulyasa,H E, 2012). Kemampuan perkembaagan yang harus di miliki anak usia dini dari rentang 0-6 tahun. meliputi 6 aspek perkembangan, yang terdiri dari nilai agama dan moral, kognitif, bahasa, motorik (motorik kasar dan motorik halus) dan seni. Motorik halus bagi anak usia dini merupakan suatu hal yang sangat penting bagi perkembangan anak. Menurut (Misiyanti,Praniti,dan Wirya,n.d.), Mengatakan bahwa motorik halus berpengaruh pada kesiapan anak dalam menulis untuk masuk kejenjang yang lebih tinggi. MenurutAtik Mulyati,(2014)mengatakan motorik halus ialah kegiatan dengan melibatkan otot-otot kecil, aktivitas yang dapat diajarkan secara bertahap sehingga dapat di mengerti anak. Kegiatan motorik yang sering dilakukan dapat membantu anak meningkatkan koordinasi jari secara bertahap. Kegiatan yang melibatkan otot-otot akan meningkatkan perkembangan motorik halus anak.

Berdasarkan observasi awal yang peneliti lakukan di TK Tunas Harapan Tandan Sari Kecamatan Tapung Hilir, keterampilan motorik halus anak kelas A belum berkembang dan sesuai harapan. Beberapa anak menunjukan belum bisa menggunting dengan benar dan rapi terutama pola lengkung. Dan adapun keterlambatan dalam keterampilan motorik halusnya terutama menggunting. Dari hasil observasi yang peneliti lakukan dari 12 anak tercatat 9 anak yang masih belum tepat menggunting sesuai dengan garis. Ada 2 anak yang memegang guntingnya belum benar dengan menggunakan dua jarinya saja, dan ada 3 anak yang cepat selesai mengguntingnya dan asal-asalan, akan tetapi ada 4 anak yang terampil sehingga hasilnya sesuai harapan. Kasus diatas menyebutkan bahwa anak kelompok A megalami kesulitan didalam pengembangan motorik halus, disebabkan oleh beberapa faktor seperti pengembangan keterampilan anak usia dini sering kali terabaikan/dilupakan oleh orang tua, bahkan guru sendiri. Faktor penyebab yang lain yaitu lemahnya koordinasi mata dan otot-otot tangan serta faktor media yang di gunakan kurang bervariasi atau monoton .

Deskripsi diatas diperlukan adanya kegiatan pembelajaran yang dapat meningkatkan keterampilan motorilk halus anak. Solusi kegiatan pembelajaran yang dapat meningkatkan motorik halus anak yaitu kegiatan menggunting dengan media daun. Kegiatan menggunting bertujuan untuk melatih koordinasi mata dan otot-otot serta konsentrasi. Kegiatan menggunting salah satu stimulus yang dapat di kembangkan oleh pendidik dalam mengembngkan motorik halus anak. Anak akan mampu mengkoordinasi indra mata dan aktifitas tangan melalui kegiatan menggunting. Keterampilan menggunting dengan media daun diharapakan menjadi alternatif meningkatkan kemampuan motorik halus.

Seiring dengan pemahaman peneliti bahwa kemampuan motorik halus anak itu sangat penting diberikan karena berkaitan tentang pengendalian gerak dan kemampuan memusatkan perhatian serta kemampuan koordinasi mata dan tangan, maka menjadi pendorong bagi peneliti untuk berupaya menemukan solusi memecahkan masalah melalui penelitian ilmiah.

Rumusan Penelitian menggunakan media daun dalam kegiatan menggunting, karena dengan media daun dapat melatih anak dalam menggunting, karena biasanya media yang di gunakan halus dan tipis. Selain itu dengan media daun yang di gunakan dalam kegiatan pembelajaran anak semakin tertarik. Oleh sebab itu perlunya dilakuakan penelitian agar kita sebagai 
guru mengetahui seberapa efektif menggunting dengan media daun TK Tunas Harapan Kecamatan Tapung Hilir Kabupaten Kampar.

\section{Motorik halus}

Menurut Atik Mulyati,(2014) mengatakan motorik halus ialah kegiatan dengan melibatkan otot-otot kecil, aktivitas yang dapat diajarkan secara bertahap sehingga dapat di mengerti anak. Kegiatan motorik yang sering dilakukan dapat membantu anak meningkatkan koordinasi jari secara bertahap. Anak yang memiliki keterampilan motorik halus yang baik akan mudah mempelajari hal-hal baru yang sangat bermanfaat dan memacu dalam menjalani pendidikan di bidang tertentu sejak dini seperti bermain musik, melukis, membuat kerajinan, membuat gambar disain dan lainnya. Sumantri (dalam Indriyani 2014: 20) mengemukakan bahwa menggunting adalah memotong berbagai aneka kertas atau bahan-bahan lain dengan mengikuti alur, garis atau bentuk-bentuk tertentu merupakan salah satu kegiatan yang mengembangkan motorik halus anak. Dengan seringnya anak melakukan kegiatan menggunting, jari jemari akan semakin lentur.

\section{Media daun}

Berbagai jenis daun dapat dipergunakan sebagai alat untuk melukis atau prakarya, seperti membuat topi, boneka dari daun, mencetak, menggunting, atau menempel daun menjadi bentuk media sesuai dengan tema. Selain itu daun juga dapat dipergunakan dalam kegiatan matematika, seperti mengukur daun, membedakan kasar dan halus mengelompokkan macam-macam bentuk daun dan mengetahui warna (Rifka R.Sidabutar, Hasanah Siahaan,2019: 44).

Belajar sambil berrmain adalah dunia anak-anak yang harus diperhatikan guru didalam kegitan pembelajarannya. Guru sebagai salah Satu kunci keberhasilan pembelajaran seyogyanya selalu mengupayakan agar pembelajaran yang berlangsung sesuai, menarik dan inovatif, karena guru perannya adalah sebagai pembaharu didalam melaksanakan tugasnya sebagai pendidik. Pentingnya pengembangan motorik halus pada anak usia dini. Pengembangan motorik halus pada anak usia dini setiap anak berbeda, demikian pula dengan penanganannya yang berbeda pula sesuai dengan lingkungan sosial dan kepribadian anak. Pengembangan motorik pada anak usia dini merupakan bagian dari kebutuhan yang sangat diperlukan dalam kehidupan sehari-hari, terutama dalam melatih otot besar dan otot kecil anak

\section{METODE}

Penelitian ini dilaksanakan di Kelas A TK Tunas Harapan Desa Tandan Sari Kecamatan Tapung Hilir Kabupaten Kampar. Adapun subyek penelitian tindakan kelas ini adalah kelas A. Jumlah siswa sebanyak 12 anak terdiri dari 6 anak laki-laki dan 6 anak perempuan. Waktu penelitian dilaksanakan pada semester genap Tahun pelajaran 2020/2021 selama bulan April - Juni Tahun 2021. Metode penelitian ini adalah penelitian tindakan kelas (Classroom Actions Research). Pelaksanaannya dibagi atas dua Siklus dan setiap Siklus .Teknik pengumpulan data yang di gunakan yaitu Observasi yakni observasi guru dan siswa dan dokumentasi. Keberhasilan penelitian Tindakan Kelas (PTK) dengan persentase. 
Prosedur penelitian yang dilakukan mengikuti model Arikunto (2014:16) yang terdiri atas tiga "komponen" yaitu: perencanaan, pelaksanaan tindakan, observasi dan refleksi. Secara rinci prosedur penelitian digambarkan sebagai berikut:

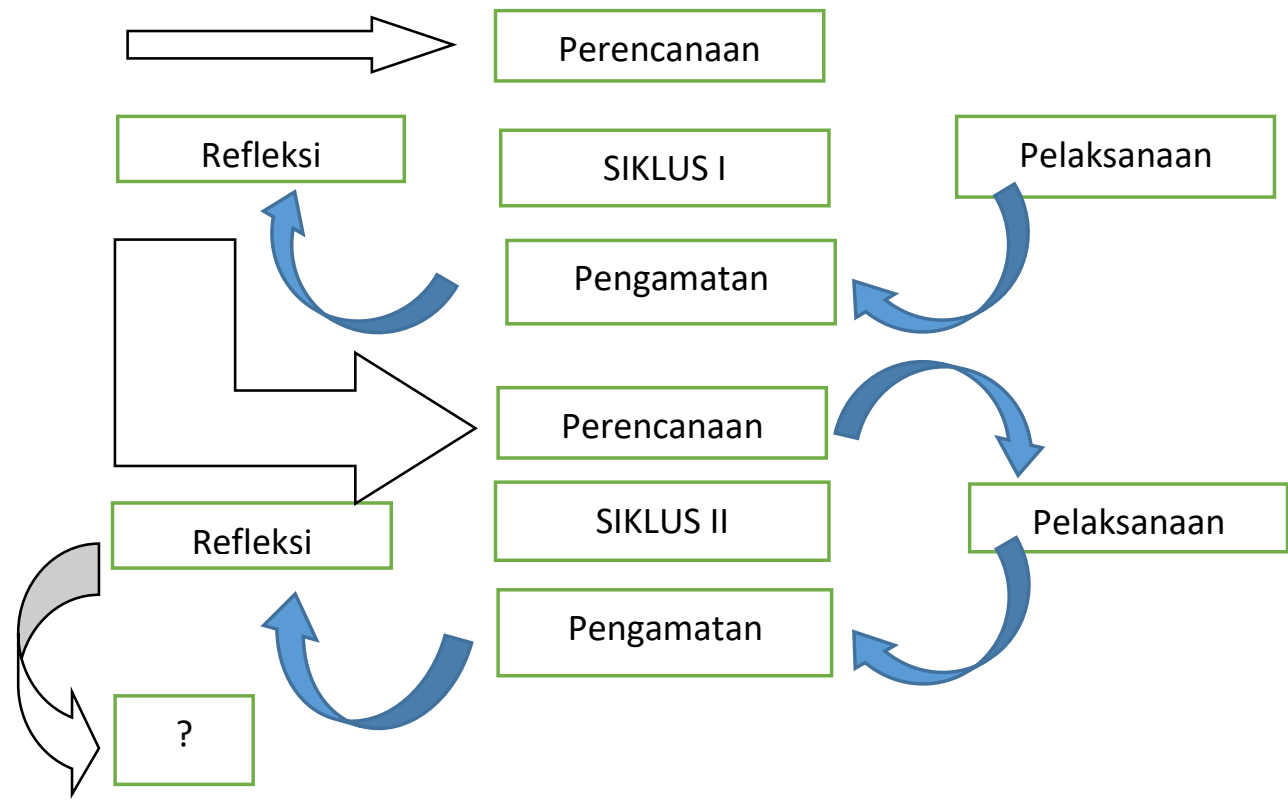

\section{HASIL PEMBAHASAN}

\section{Pra Tindakan.}

Pada penelitian pratindakan,guru mengajar dengan tema alam semesta dan sub tema benda langit. Pada masa pratindakan peneliti belum memasukkan media daun. Hanya mengobservasi pembelajaran yang masih terpaku dengan buku paket. Pada kegiatan inti anak menggambar pola sendiri yakni dengan pola miring,lurus dan lengkung di kertas hvs lalu mengguntingnya satu persatu. Ada anak yang kertasnya rusak ada yang hanya diam dan meminta guru untuk membantunya, ada anak yang sudah dapat menggunting rapi.Namun masih banyak anak yang kesulitan dalam kegiatan menggunting mereka hanya diam dan mengguntingnya dengan asal-asalan atau dengan meminta bantuan guru untuk membantunya menggunting. Hasil pengamatan pratindakan kelas A TK Tunas Harapan sebagai berikut :

Tabel 1. Rekapitulasi data motorik halus Pra Tindakan

\begin{tabular}{|c|c|c|c|c|c|}
\hline No & Kategori & Kriteria & Skor & Jumlah siswa & Jumlah \% \\
\hline 1 & BSB & $76-100$ & 4 & 0 & $0,00 \%$ \\
\hline 2 & BSH & $57-75$ & 3 & 2 & $16,66 \%$ \\
\hline 3 & MB & $41-55$ & 2 & 9 & $75 \%$ \\
\hline 4 & BB & $\leq 41$ & 1 & 1 & $8,33 \%$ \\
\hline \multicolumn{7}{|c|}{ Persentase rata-rata } \\
\hline
\end{tabular}

Berdasarkan tabel diatas diperoleh data bahwa motorik halus anak keterampilan memenggunting anak dikelas A TK tunas Harapan pratindakan menunjukkan kriteria berkembang sesuai harapan 2 anak, kriteria mulai 
berkembang sebanyak 9 anak sedangkan yang belum berkembang terdapat I anak. berdasarkan tabel rekapitulasi data, persentase keterampilan motorik halus melalui kegiatan menggunting anak belum mencapai keberhasilan, maka dilakukan perbaikan pembelajaran selanjutnya.

\section{Siklus I}

Setelah peneliti melakukan pengamatan terhadap anak kelas A TK Tunas Harapan maka diperoleh hasil yang menunjukkan perkembangan kemampuan anak dalam kegiatan menggunting pada siklus I, hasilnya adalah Tabel 2

Tabel 2. Data Pencapaian Rekapitulasi Siklus I

\begin{tabular}{|l|l|c|c|c|c|c|c|}
\hline N0 & Nama & P1 & P2 & P3 & Jumlah & Persentase & Kategori \\
\hline 1 & ALK & 7 & 10 & 10 & 22 & $61,11 \%$ & BSB \\
\hline 2 & DMS & 6 & 9 & 10 & 20 & $55,55 \%$ & BSH \\
\hline 3 & BTG & 7 & 11 & 12 & 20 & $55,55 \%$ & BSH \\
\hline 4 & PTR & 6 & 12 & 11 & 24 & $66,66 \%$ & BSB \\
\hline 5 & ARD & 8 & 10 & 11 & 22 & $61,11 \%$ & BSB \\
\hline 6 & NND & 10 & 10 & 10 & 30 & $83,33 \%$ & BSB \\
\hline 7 & SFL & 6 & 6 & 6 & 18 & $50 \%$ & MB \\
\hline 8 & KSY & 8 & 7 & 9 & 24 & $66,66 \%$ & BSH \\
\hline 9 & ABZ & 7 & 7 & 6 & 20 & $55,55 \%$ & BSH \\
\hline 10 & AKR & 7 & 7 & 11 & 24 & $66,66 \%$ & BSH \\
\hline 11 & STA & 6 & 7 & 7 & 20 & $55,55 \%$ & MB \\
\hline 12 & PTA & 6 & 6 & 7 & 19 & $52,77 \%$ & MB \\
\hline \multicolumn{7}{|l|}{ Rata-Rata kelas } & \\
\hline
\end{tabular}

Berdasarkan hasil dari tabel diatas dapat diketahui bahwa persentasi peningkatan motorik halus anak pada pertemuan I sampai 3 siklua I mengalami peningkatan sebesar $68,87 \%$ belum ada anak yang mencapai kategori Berkembang Sesuai Harapan (BSH) dan Berkembang Sangat Baik (BSB) pada siklus I Sudah mulai ada. Anak dengan peningkatan kemampuan perkembangan BSB yaitu sebanyak 3 anak dengan presentase $27,5 \%$ dari seluruh jumlah siswa, sedangkan anak dengan kategori BSH sebanyak 5 anak dengan presentase $45 \%$ dari seluruh siswa. Pada anak dengan tahap Mulai Berkembang (MB) adalah 3 anak dengan presentase $27,5 \%$ dari seluruh jumlah siswa.

\section{Siklus II}

Setelah melakukan pengamatan terhadap anak didik kelompok A TK Dahlia maka diperoleh hasil yang menunjukkan perkembangan kemampuan anak yang meningkat sangat baik dalam mengenal angka pada siklus II penelitian, adapaun hasilnya adalah sebagai berikut : 
Tabel 3. Rekapitulasi Siklus II

\begin{tabular}{|c|c|c|c|c|c|c|c|}
\hline No & Nama & $\mathrm{P} 1$ & P2 & P3 & Jumlah & Rata-Rata & Kategori \\
\hline 1 & ALK & 8 & 10 & 10 & 28 & $77,77 \%$ & BSB \\
\hline 2 & DMS & 7 & 11 & 11 & 29 & $80,55 \%$ & BSB \\
\hline 3 & BTG & 8 & 12 & 12 & 30 & $83,33 \%$ & BSB \\
\hline 4 & PTR & 12 & 12 & 12 & 36 & $100 \%$ & BSB \\
\hline 5 & ARD & 10 & 12 & 12 & 34 & $94,44 \%$ & BSB \\
\hline 6 & NND & 12 & 12 & 12 & 36 & $100 \%$ & BSB \\
\hline 7 & SFL & 8 & 8 & 12 & 30 & $83,33 \%$ & BSB \\
\hline 8 & KSY & 11 & 12 & 12 & 36 & $100 \%$ & BSB \\
\hline 9 & $A B Z$ & 8 & 7 & 12 & 27 & $75 \%$ & $\mathrm{BSH}$ \\
\hline 10 & AKR & 8 & 8 & 12 & 28 & $77,77 \%$ & BSB \\
\hline 11 & STA & 8 & 10 & 12 & 28 & $77,77 \%$ & BSB \\
\hline 12 & PTA & 8 & 7 & 12 & 27 & $75 \%$ & $\mathrm{BSH}$ \\
\hline
\end{tabular}

Berdasarkan hasil dari tabel diatas dapat diketahui bahwa persentasi peningkatan motorik halus anak pada pertemuan I sampai 3 siklus II mengalami peningkatan sebesar $84,95 \%$. Hasil penelitian siklus ke II menunjukkan angka peningkatan yang sangat baik.. Selain itu penggunaan media daun yang lebih bervariasi membuat anak senang dan menumbuhkan rasa ingin tahu yang lebih ketika sikap anak menunjukkan sikap yang gembira maka kemampuan dalam menerima pembelajaran juga akan lebih mudah.

\section{PEMBAHASAN}

Peningkatan keterampilan motorik halus kegiatan menggunting pada anak kelas A TK Tunas Harapan Tapung Hilir terlihat dari hasil persentase prasiklus sampai Siklus II. Berdasarkan hasil observasi pada pratindakan kegiatan menggunting anak yang mencapai kriteria berkembang sesuai harapan 2 anak $(16,66 \%)$,mulai berkembang 9 anak $(75 \%)$ dan belum berkembang 1 anak (8,33\%). Pada Siklus I anak yang mempunyai kriteria berkembang sangat baik 4 anak (33,33\%). Pada siklus II, anak dengan kriteria berkembang sangat baik sebanyak 10 anak (83,33\%). Presentase peningkatan motorik halus anak pada pratindakan, siklus I dan siklus II dapat di lihat pada gambar grafik di bawah ini, sebagai berikut: 


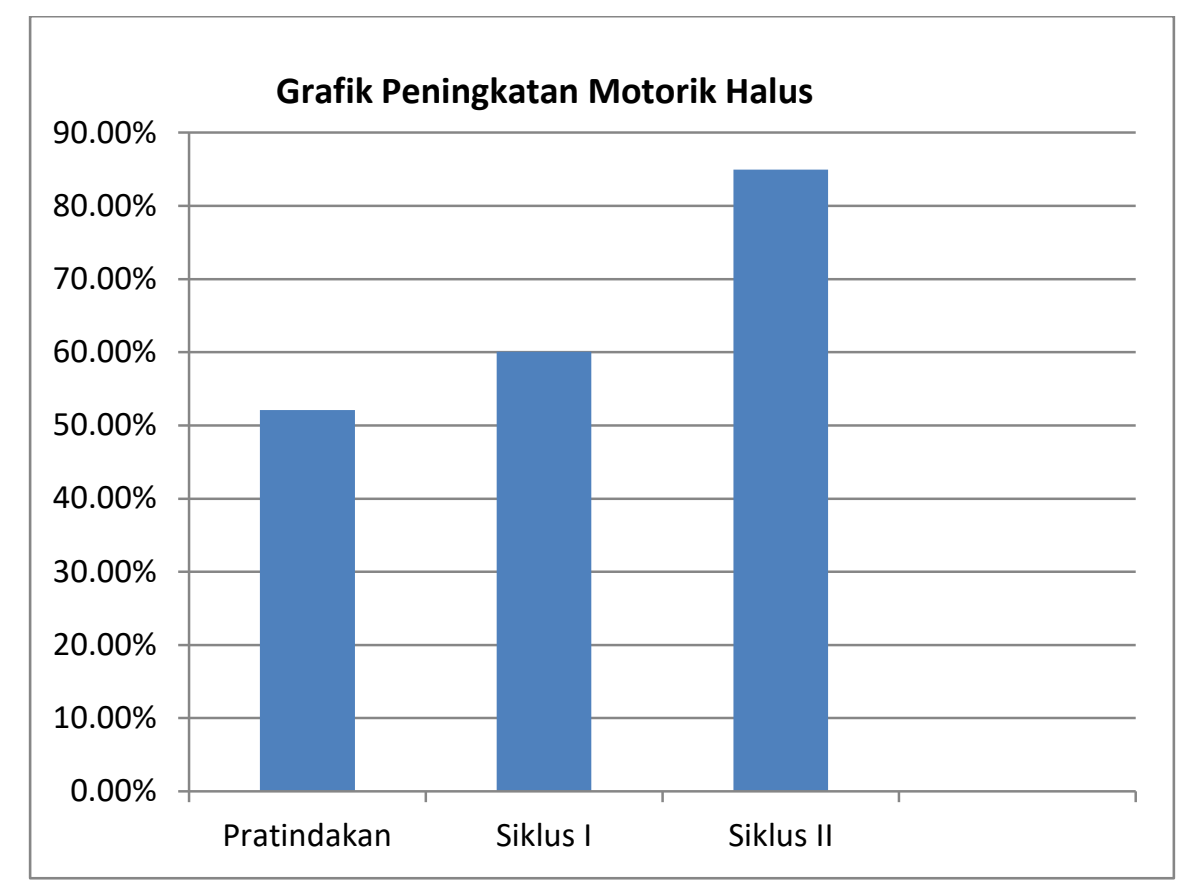

Grafik Perbandingan Motorik Halus Pratindakan,Siklus I, Siklus II

\section{KESIMPULAN}

Berdasarkan hasil penelitian dan pembahasan yang telah dilakukan dalam 2 Siklus yaitu 1 Siklus terdapat 3 kali pertemuan dalam penelitian tindakan kelas (PTK) maka dapat diperoleh kesimpulan bahwa pembelajaran motorik halus kegiatan menggunting dikelas A TK Tunas Harapan dapat ditingkatkan dengan media daun.

Hasil penelitian dapat dilihat dari proses menggunting dan meningkatnya kemampuan motorik halus kegiatan menggunting daun untuk kriteria berkembang sangat baik pada setiap siklusnya. Pada saat pratindakan menunjukkan hasil 8,33\% atau Cuma ada 1 anak yang berkembang sangat baik, Pada siklus I meningkat menjadi $27,77 \%$.

\section{DAFTAR PUSTAKA}

Annisa, K (2016). Peningkatan Kemampuan Motorik Halus Anak Melalui Kegiatan Kolase Pada Anak Kelompok B di TK mutiara Kamoung Godang Bangkinang. Universitas Pahlawan, Bangkinang : Skripsi Tidak Dipublikasikan

Arikunto, dkk (2016). Penelitian Tindakan Kelas. Jakarta : PT Bumi Aksara

Departemen Pendidikan Nasional (2007). Menggunting Panduan PraktisPendidik PAUD. Semarang.

Diutatik, Peningkatan Kemampuan Motorik Halus Melalui Media Playdough Anak Kelompok A Di TK Dwi Kunti Surabaya (online), (http://deim,ac.id)diunduh19 maret 2016),2016

Fauziddin, (2018) Meningkatkan Kemampuan Motoric Halus Melalui Teknik Mozaik pada Anak Kelompok B di TK Perdana Bangkinang Kota (https://doi org/10.31331/sece.v1i1.581) di unduh 16 Maret 2018),2021 
Gunarti, W, dkk (2010). Metode Pengembangan Prilaku dan Kemampuan Dasar AUD. Jakarta : Universitas Terbuka

Indriyani Fitria, (2014) Peningkatan Keterampilan Motorik Halus Melalui Kegiatan Menggunting Dengan Berbagai Media Pada Anak Usia Dini Di Kelompok A TK Aba Gendingan, Kecamatan Kalasa Kabupaten Slrman Yogjakarta, Universitas Pendidikan,Yogyakarta: Skripsi tidak dipublikasikan.

Laily.Safitri (2018) Implementasi Menggunting Pola Dalam Mengembnagkan Motoric Halus Anak Di TK Apik Darussalam Langkapura Bandar Lampung, Universitas Pendidikan Islam Negri Raden Intan Lampung: Skripsi tidak dipublikasikan.

Lestari, Yeni Tri. 2015, Meningkatkan kemampuan Motorik Halus Anak Melaui Kegiatan Kolase Dengan Berbagai media. JurnalPendidikan Anak Usia Dini Universitas: Islam Yogyakarta

Nurhayani (2008). Tujuan Pengembangan Motorik Halus. [online] Tersedia dalam: e-dukasi.net : 2008/tujuan-pengembangan-motorik-halus/ [diakses 2008]

Nikma (2018) Meningkatkan Keterampilan Motorik Halus Melalui Kegiatan Menggunting Dengan Media Kertas Dan Daun Pada AUD Di Kelompok A Di RA Miftahul Ulum II Lumbang"Jurnal Annual International Conference on Islamic Education.The $3^{\text {rd }}$

Menteri Pendidikan dan Kebudayaan (2015). Peraturan Menteri Pendidikan Nasional. Jakarta : Departemen Pendidikan Nasional.

Permendiknas No.58 . (2008). StandarPendidikan Anak Usia Dini. Jakarta Kemendiknas

Phamadi, dkk (2014). Seni Keterampilan Anak. Tangerang Selatan : Universitas Terbuka

R.Sidabutar, H. Siahaan (2019)" Peningkatan Motorik Halus AUD Melalui Pemanfatan Media Daun Dalam Kegiatan Pembelajaran"Jurnal Of IslamicEarly Chaildhood Education.Vol.2 No.1

Septiana 03(2016). Bahan-bahan dalam Kegiatan Menggunting.[online] Tersedia dalam:blogspot.com. id : 2016/bahan-bahan dalam-kegiatanmenggunting/ [diakses 2016]

Sujiono, B, dkk (2010). Metode pengembangan fisik. Jakarta : Universitas Terbuka.

Suryana Dadan.2016. Pendidikan Anak Usia Dinidan Aspek Perkembangan. Jakarta: Kencana

Suryani, Alimni. 2012. Peningkatan Motorik Halus Anak Melalui Mengisi Pola Gambar dengan Daun Kering di TK Andessa Pariaman. Jurnal IImiah PGPAUD Volume 1.No. 1.

Suyadi (2010). Psikologi Belajar Pendidikan.Yogyakarta : Pedagogia 
Undang-undang Republik Indonesia No 23 tahun 2002 tentang Perlindungan anak

Undang-Undang Nomor 20 Tahun 2003 tentang Sistem Pendidikan Nasional

Wandi.Mayar.2020.Analisis Kemampuan Motorik Halus dan Kreativitas padaAnak Usia Dini,Melalui Kegiatan Kolase. Jurnal Obsesi Volume 1-4 No 351-358

www. Scribd. Com/ document/318730272/meningkatkan/kemampuan/motorik /halus/anak/melalui/kegiata/menggunting/bervariasi/PAUD/Terpadu/islam/ Alhara main/Sawah/Dangka/Kecamatan/Tilat 